\title{
Assessing Emerging ICT-Enabled Governance Models in European Cities: Results from a Mapping Survey
}

\author{
Gianluca Misuraca $^{1,2}$, Enrico Ferro ${ }^{3}$, and Brunella Caroleo ${ }^{4}$ \\ ${ }^{1}$ European Commission Joint Research Centre, \\ Institute for Prospective Technological Studies (IPTS), Information Society Unit, Seville, Spain \\ \{gianluca.misuraca\} @ec . europa.eu \\ ${ }^{2}$ Ecole Polytechnique Fédérale de Lausanne (EPFL), \\ College of Management of Technology, Lausanne, Switzerland \\ \{gianluca.misuraca\} @epfl.ch \\ ${ }^{3}$ Istituto Superiore Mario Boella, Technology to Business Intelligence Unit, \\ Via Boggio 61, 10138 Torino, Italy \\ \{enrico.ferro\}@ismb.it \\ ${ }^{4}$ Politecnico di Torino, Department of Production Systems and Business Economics, \\ Corso Duca degli Abruzzi 24, 10129 Torino, Italy \\ \{brunella.caroleo\} apolito.it
}

\begin{abstract}
The paper presents the preliminary results of an exploratory survey conducted by the Information Society Unit of the Institute for Prospective Technological Studies (IPTS) of the European Commission. The main goal of the research is to deepen the understanding of the interplay between ICTs and governance processes at city level in the EU by looking at what new ICTenabled governance models are emerging in European cities and what are their key socio-economic implications. In this preliminary phase efforts have been directed towards addressing the following research question: what key city governance policy areas ICTs impact most and what governance changes are driven by ICTs? This questions have been investigated through a questionnaire based online survey. The evidence collected provided a comprehensive mapping of the use of ICTs in European cities as well as the views of policy makers, city government officials, practitioners and researchers, on the way ICTs are influencing governance processes. The evidence collected shows that new ICT-enabled governance models are emerging, and it allowed to identify the main dimensions of change, drivers, barriers, enablers and characteristics, as well as opportunities, risks and challenges associated with them.
\end{abstract}

Keywords: ICTs, Governance, Policy Research, Cities, Benchlearning.

Disclaimer: The views expressed in this paper are purely those of the authors and may not in any circumstances be regarded as stating an official position of the European Commission.

Copyright: The EU retains all copyrights of the data published in this paper. 


\section{Introduction}

In spatial, economic and cultural terms, the Information Society is dominated by cities and metropolitan regions [1]. Around 70\% of all Europeans live in cities. They are throughout recognized as the dominant space of Information and Communication Technologies (ICTs) industries and uses, but they are also the area where most of the poor, the disadvantaged and excluded live. They are the government layer closest to neighborhood and citizen initiatives and local non-government organizations. Furthermore, city governments are in an excellent position to engage in necessary strategic partnerships across the public, private and third sector. Cities can therefore play a key role in the field of ICT-enabled governance, but especially when their capacities are used in an integrated way that allows the highest impact on social cohesion and local economies [2]. In addition to being close to citizens and business, most public services are offered on the city government level; in some EU member states this share amounts to $70 \%$ of all public services.

As a matter of fact, based on the analysis of the state of the art of research and practice in this field, it can be observed that while experiments and pilot projects are taking place at different governance level, it is at the city level that the appropriate use and integration of ICTs in the governance mechanisms can support social and institutional innovation, particularly in empowering officials and community representatives; ensuring social inclusion; providing timely, efficient, transparent and accountable services; improving the management of administrative operations; facilitating planning and policy making processes; monitoring and recording political decisions and assessing socio-economic impacts in the municipalities and their locale.

However, while research in the overlapping areas of e-Government, e-Governance, e-Participation and e-Inclusion at city level has been examining mainly the supply side and the sophistication of e-Services offered; reliable data on measuring the effects of ICT-enabled applications on governance processes and the impacts on specific policy areas are lacking, and where existing not yet harmonized, incomplete or difficult to use for comparison in other contexts or at EU level.

For this reason, following a preliminary analysis and consultations with stakeholders, IPTS designed and launched jointly with EUROCITIES a 'mapping survey $^{\prime 1}$ in order to identify key city governance policy areas most impacted by ICTs and select significant case studies to be analysed in depth in the following phases of an exploratory research on emerging ICT-enabled governance models in EU cities. .

In this first phase of the research efforts have been directed towards addressing the following research question: what key city governance policy areas ICTs impact most and what governance changes are driven by ICTs?

The paper is structured as follows: first of all it outlines the conceptual framework underpinning the research and the methodological approach followed for the survey. The results of the survey and some preliminary conclusions and indications on the future steps of the research are then presented.

1 The survey has been conducted during the period 15 November - 15 December, further extended until 31 December 2009 due to the high interest raised. 


\section{Conceptual Framework}

The notion of urban governance, which is often considered as an alternative to traditional approaches to government (centralised, hierarchical, top-down, bureaucratic) promotes an approach based on public action networks and mechanisms aimed at cooperation, organisation and even integration in the systems and mechanisms of a wide diversity of public and private stakeholders (a polycentric, network-based, horizontal, cross-disciplinary, process-based, bottom-up approach) [3]. There are a number of different theories generally put forward to explain the emergence of the concept of urban governance, according to the various problems and changes in society which the concept attempts to address [4].

Research in this area, however, does not usually consider the impacts of major economic trends and their consequences in terms of the spatial distribution of production factors (capital and workforce) at urban level [5]. Structural analysis of the linkages between the high-value added assets of the digital economy is not considered from most research on urban governance and local development [6].

Considering governance as a multidimensional construct, the focus of our research is instead on the way the different stakeholders interact when introducing ICTenabled services and innovations in specific policy areas and the way these interactions affect institutions and communities, and the related governance processes. The governance changes under scrutiny are both technologically and socially driven and manifest themselves in new governance models and public management practices, revised institutional processes and organisational structures. In particular, the research is based upon the belief that the socio-economic perspectives, which stand at the interface between analyses of individual behaviour and wider societal structures, are well placed to elucidate the impacts of ICTs on governance.

In the theoretical framework underpinning the research we therefore combine neoinstitutionalist perspectives [7] with constructivist approaches to policy and sociopolitical institutions such as the ones developed by Schmidt [8] and Berger and Luckmann [9]. This is especially useful in investigating how social phenomena develop in the particular social contexts characterized by ICTs [10].

The attention of our analysis is in fact on the way the different stakeholders interact when introducing ICTs in governance systems, the way these interactions affect institutions and communities, and the related decision-making process. Two main issues are specifically investigated: 1) the changes produced by ICTs on the governance processes ${ }^{2}$, (e.g. regulatory and legal frameworks, organisational and administrative procedures, roles of various stakeholders involved, etc.) and consequently the effects on decision-making, public management and service delivery; and 2) the socio-economic implications at policy level.

${ }^{2}$ We refer here to changes due to ICTs both at inter-administration level and with regard to the relationship between the government and the different stakeholders involved in the specific service, either directly provided by the city government or mediated by other actors as intermediaries. 
In brief, the research has a twofold objective. On the one hand, it intends to contribute to inform policy-makers about the implications of change produced by new and emerging ICT-enabled governance models in EU cities and demonstrate evidence of impacts on the specific policy areas under investigation. On the other hand, the research aims also at contributing to consolidate scientific evidence of impacts of ICT-enabled applications on city governance models in the EU.

Therefore, for this research, governance is defined as the process of decisionmaking and the process by which decisions are implemented and ICT-enabled governance ${ }^{3}$ as 'the use of ICTs to comprehensively: (1) simplify and improve the internal administrative operations of government and their relations with other bodies involved in public management and service delivery; (2) facilitate public service interaction between government, citizens and other stakeholders (legislative bodies, private sector, civil society organizations, self-organised communities), thus enabling better citizen participation and overall monitoring and evaluation of decision-making processes and their implementation; and (3) ensure inclusiveness and equal opportunity for all' [11]. This concept is to be intended as an 'ideal model' to indicate the comprehensive framework enfolding a broad range of informal and formal descriptions to represent core aspects of the governance process, including policy and decision -making, strategic and operational processes, legal and organisational structures, working practices, interactor relationships, and the public service delivery, aiming at creating -in a proactive manner- public value.

\section{Methodological Approach}

The methodological approach used for the first phase of the research is based on grounded-theory / action research and involved an online survey addressed to city government in Europe in order to identify perceptions on the impact of ICTs on governance. The data collected through the survey have been analyzed using statistical techniques such as clustering and complemented with consultations with stakeholders and a focus group meeting with representatives of city governments and researchers to validate the findings and define the next activities of the research.

The survey gathered 62 answers from cities in 27 European countries, covering 25 EU27 member States plus Croatia and Switzerland. It is therefore highly representative of different governance models and ICT-enabled services currently provided by European cities as the sample includes cities covering about $93 \%$ of EU27. In particular, out of the 62 cities respondents to the survey, 44 cities $(71 \%)$ are 'large cities' (with more than 200.000 citizens). Other respondents to the survey are cities or counties with a smaller or larger population.

Concerning the respondents profile, the distribution looks as follows: $41 \%$ (25) are City Government officials (e.g. CIO/Head of IT Departments, etc.); 26\% (16) are researchers; $19 \%$ (12) are policy or technical advisors, while only 3\% (2) are City Manager/Mayor or their representatives (Figure 1).

${ }^{3}$ Source: [11], based on: OECD, 2001 and 2006; UNDP, 1997, 2003, 2009; UNDESA, 2007. 


\section{Survey's Results}

Results from the first part of the survey, clearly indicate that respondents consider ICTs are producing changes on governance processes in many respects. About $65 \%$ of the respondents have indicated ICTs are producing a significant change on governance processes and $11 \%$ even pointed out ICTs are generating very significant change (see Figure 1). These results are of particular significance as there seems to be a strong opinion on the impacting role of ICTs in generating effective change in city governance processes.

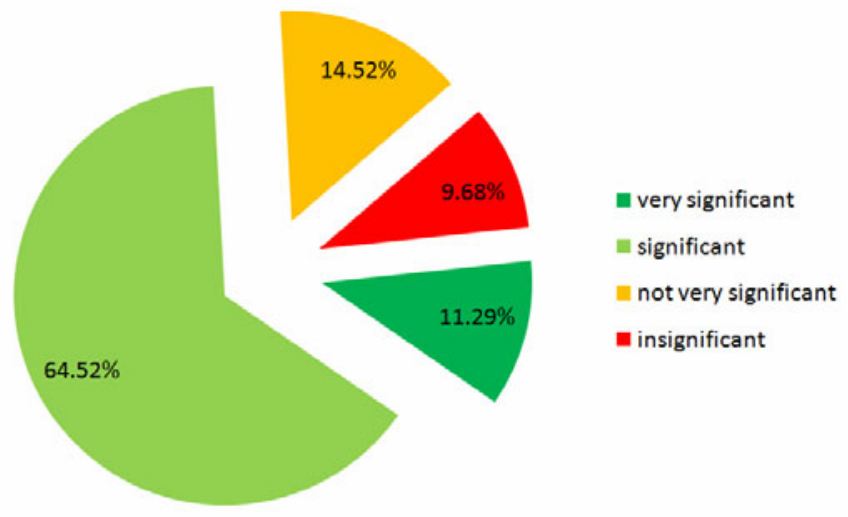

Fig. 1. City Governance changes due to application of ICTs

When analysing more specifically which are the policy areas most impacted by ICTs, a fragmented picture emerges. Rather than on specific policy areas, ICTs seem to impact city governance across the board. Moreover, to better understand in which policy areas these impacts were produced, the order of preference given by respondents for each policy area was analysed. Two messages emerge from figure 2 .: information and communication, economic development, energy and environment and healthcare seem to be the most impacted policy areas (if looking at the aggregate of $1^{\text {st }}$ and $2^{\text {nd }}$ choice). At the same time a more generalized and cross-sectional impact seems to be perceived across all policy areas.

The case of Social Inclusion is of particular interest as it does not present any 'first choice' but it is indicated by about $60 \%$ of the respondents as a second choice. The policy area of Employment instead has not been indicated by any of the respondents as 'first choice', and it actually presents a limited relative score also as second choice (about 25\%), thus making it the domain considered as the less affected by ICTs.

However, it must be considered that responses on some of the policy areas are influenced by the fact that governance systems are different in different countries, and that city government administrative competences and responsibilities are diverse in various governance systems. For example, Employment policies in many cases are not direct responsibility of the city level government. 


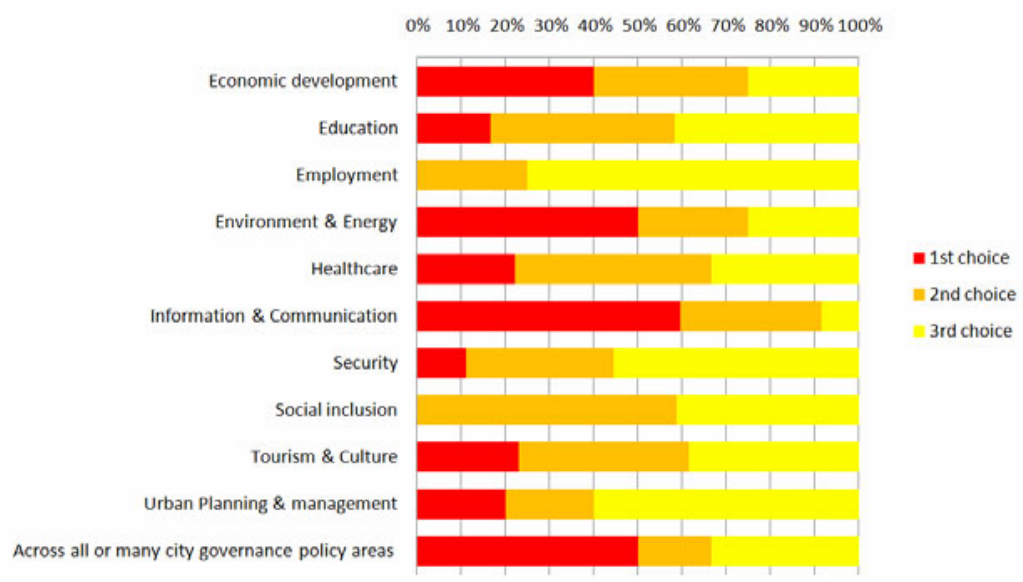

Fig. 2. Policy areas most impacted by ICTs disaggregated according to order of choice

Based on the responses to the survey and on the analysis of the examples provided, it was also possible to make a preliminary categorization of what has changed in the governance process according to respondents (see Figure 3).
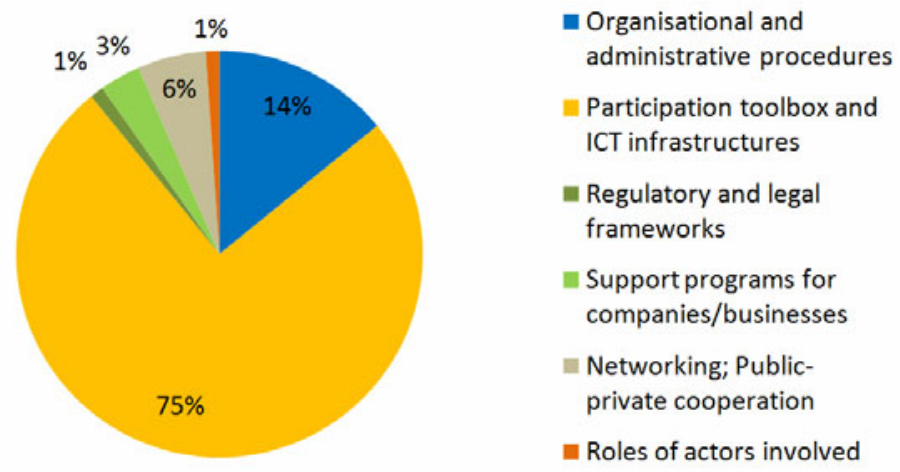

Fig. 3. Effects of ICT-driven changes on governance processes

\begin{abstract}
A large majority of respondents (75\%) associated initiatives driven by ICTs with changes in the ICT infrastructure and what can be defined as the participation toolbox, $14 \%$ of the respondents indicated ICTs is generating changes in terms of organizational and administrative procedures and a $6 \%$ on Networking and Public and Private Cooperation. A limited number of respondents $(3 \%)$ indicated that ICTs are producing changes in the way of organizing and delivering support programs for companies and to start-up new businesses and only $1 \%$ considers that ICTs is changing regulatory and legal framework and the roles of actors involved in the governance process.
\end{abstract}


Furthermore, focusing on the governance function which is impacted most by ICTs, the survey provides evidence that ICTs are considered to be more impacting at the service delivery level (46\% of response rates). However, $34 \%$ of response rates indicates that ICTs are also producing significant effects on the decision making process. Impacts on legal and regulatory frameworks directly linked to ICTs are instead more limited, but still counting for $20 \%$ of the response rate.

Crossing data between governance functions most affected by ICTs and policy areas, confirms the general sentiment that ICTs impact on governance functions is distributed equally in most policy areas. Some exceptions can be found in the area of Employment, where changes are clearly mainly of legal and regulatory nature.

Interesting are the cases of Urban Planning and Information and Communication which present a quite high impact of ICTs on decision-making process (40\%), while the domains of Social Inclusion and Tourism and Culture, in addition to Employment, do not present changes in this function, ICTs impacting only on service delivery and regulatory frameworks. On the contrary, the case of Environment and Energy shows no changes affected by ICTs on legal and regulatory frameworks.

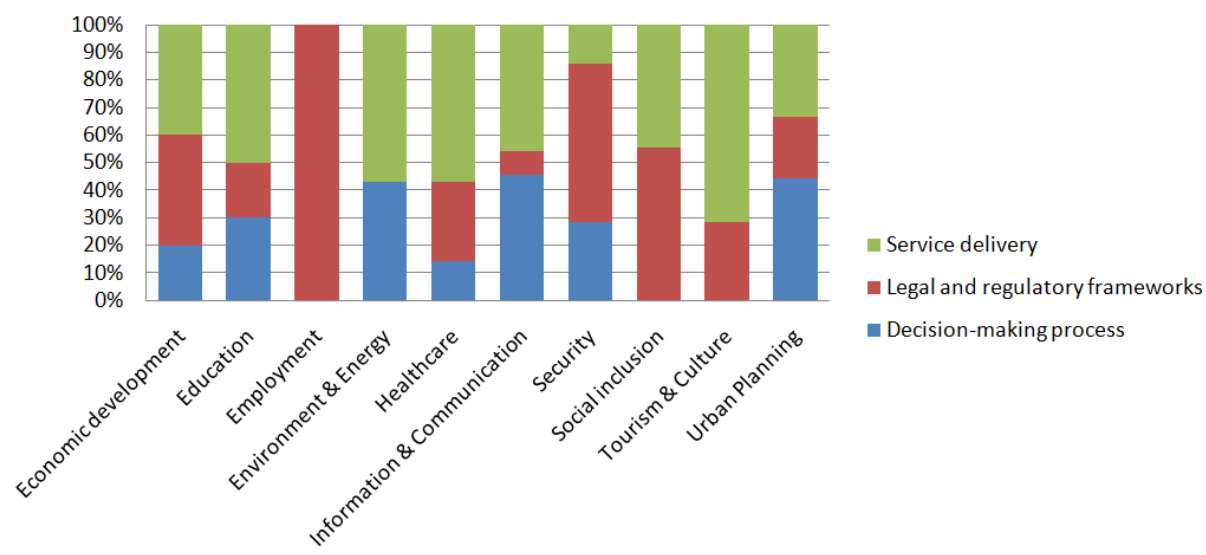

Fig. 4. Governance functions most impacted by ICTs per policy area

Finally, an analysis of the impacts of ICTs in different geographic areas in Europe shows a quite interesting situation (see Figure 5). It seems in fact that while in North Europe ICTs are considered to have a strong impact (with $22 \%$ very significant, $73 \%$ significant and only $5 \%$ not very significant), the situation is much more scattered in other regions. In central Europe, for example, there is almost a balance between the significant impact of ICTs $(63 \%)$ and the not very significant impact $(47 \%)$. In the Mediterranean and Eastern Europe areas instead, it seems that ICTs have a less significant impact on changes in the governance process.

This analysis somehow confirms general literature on administrative and cultural traditions of governance models in Europe, where we can see that many factors affecting public administration performance and bureaucratic traditions are based on different governance models. 


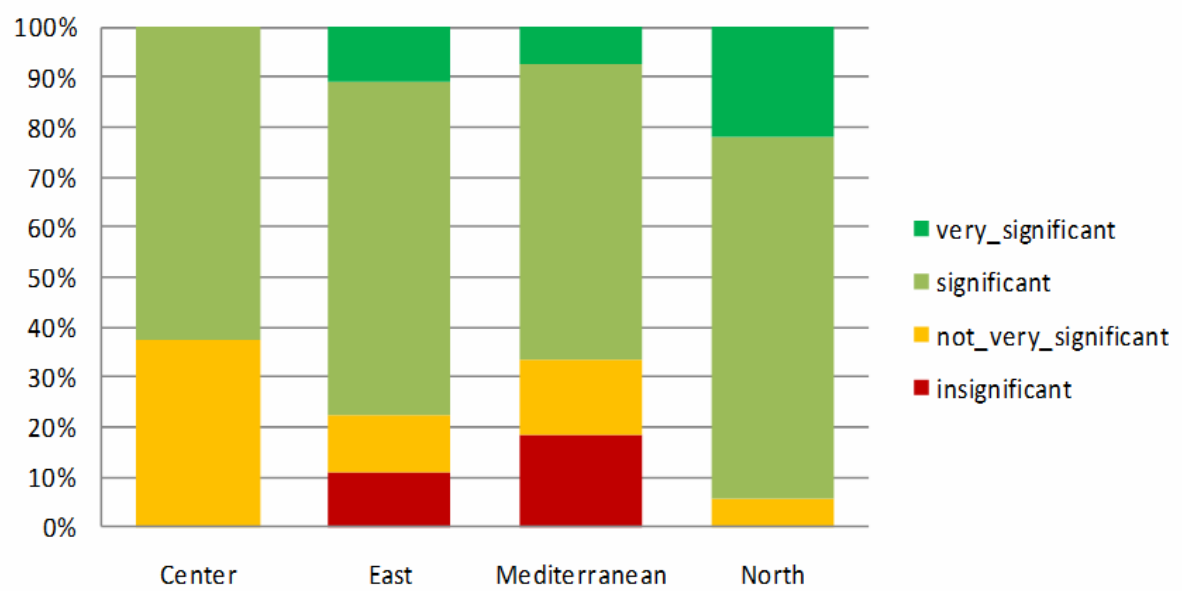

Fig. 5. Impact of ICTs in Europe per geographic areas

The implication of these considerations for the current research is precisely that when defining an ICT-enabled governance model at the level of city government, the administrative traditions and cultural context on which ICTs are applied should also be considered. This is of particular importance when then attempting to assess the changes driven by ICTs through impact assessment. Just to give an example, indicators of cost savings in term of human resources or of improved effectiveness through the redeployment of resources freed-up from the success of an ICTenabled application (i.e. resources moved to the front-end thanks to efficiency gains in the back-off) must take into account that in certain countries rules and regulations, labour contracts negotiations with public employment trade unions and the likes, can hinder and/or delay the exploitation of such gains. In such instances, a strictly defined indicator of human resources cost saving would find difficulties to be accepted by all European administrations. In the same way, to measure the inter-operability and degree of shared/joined-up services, it is necessary to take into account that the likelihood of reaching such objectives depends also on the governance structure of the state (not only at the city level then) and it is reasonable to assume them to be more difficult to achieve in decentralised and federalist states.

In this connection, the cluster analysis of ICTs impact on governance and policy areas in European cities allowed us to identify 5 clusters (see Figure 6) of which 4 have been considered relevant for the analysis mentioned above (see Table 1).

The cluster analysis was also instrumental to identify possible case studies representatives of different governance models in Europe to be further analysed in depth. It is clear that the clustering, while does not provide us with definitive conclusions about the kind of ICT-enabled governance models in EU cities, will facilitate the next steps of the research in classifying possible impacts of ICTs on city governance models. 


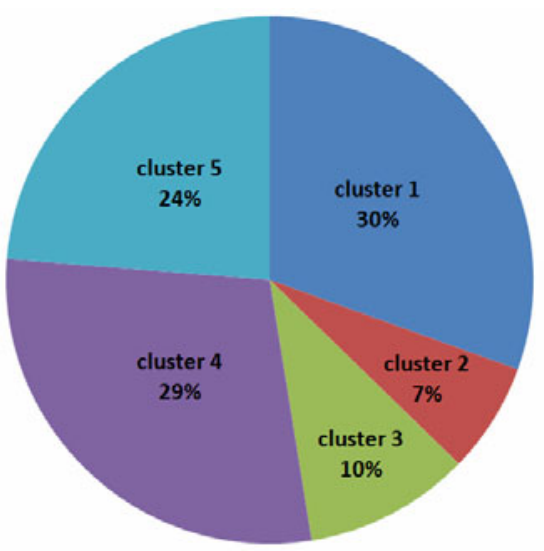

Fig. 6. Clusters of ICTs impact on governance and policy areas in EU cities

Table 1. Description of Clusters of ICTs impact on governance and policy areas in EU cities ${ }^{4}$

1

Overall very significant impact of ICTs on governance and especially on decisionmaking processes and characterized by changes in ICT infrastructure and participation toolbox, mainly in the policy area of information and communication (e.g. public relations, citizens' participation engagement)
2

Overall significant impact of ICTs on governance and especially on service delivery mechanisms and characterized by changes in the policy area of economic development (e.g. industry, business and SMEs, taxation, etc.)

Overall significant
impact of ICTs on
governance and
especially on service
delivery mechanisms
and characterized by
changes in the policy
area of information
and communication
(e.g. public relations,
citizens' participation
and engagement)

$\begin{array}{ccc}\mathbf{5} & \\ \text { Overall } & \text { not } & \text { very }\end{array}$ significant impact of ICTs on governance, but when impact is present this is especially on service delivery mechanisms and characterized by changes in the policy areas of Urban Planning and Management and Tourism and Culture and manifested by changes in ICT infrastructure and participation toolbox

In addition to the impacts of ICTs on city governance policy areas, the survey was also looking at exploring whether new forms of ICT-enabled governance models are emerging at city level in Europe. Findings from the survey indicate that the majority of cities $(60 \%)$ consider new ICT-enabled governance models are emerging, either clearly $(15 \%)$ or to some extent $(45 \%)$. However, an important number of respondents (36\%) said that 'they don't know', either because it is too early to judge (33\%), or in some cases because it is impossible to tell (3\%). Only $3 \%$ of respondents indicate that no new governance models are emerging due to ICTs. Responses to this part of the survey indicate a very promising perception of the emergence of new ICT-enabled governance models, thus opening up the road for further analysis in this direction.

${ }^{4}$ For the cities grouped under Cluster 3, it was not possible to find common characteristics. 
Moreover, the survey also collected qualitative examples and statements of city views on emerging ICT-enabled governance models, with specific regard to the main barriers to change and the main foreseeable risks, the main enablers of change and the key characteristics of the new emerging ICT-enabled governance models.

In particular, based on the analysis of the examples provided by cities, it has been possible identify some of the main drivers of change on governance driven by ICTs. These changes are reported here not in order of importance but as a list of key issues, as pointed out by the respondents to the survey.

\section{Drivers of changes for ICT-enabled governance models}

1) Efficiency \& Effectiveness of public service delivery

2) Quality of public service provision \& enhancement of users' satisfaction

3) Trust on public agencies \& Citizens' participation in the decision making processes

4) Performance Measurement \& motivation of civil servants

5) Reengineering and standardisation of public administration processes;

6) Prioritisation/customisation of public services (focusing on high-impact services and strategic policy areas, and in particular focusing on inclusion)

7) Streamlining governance processes to cope with increased ICT-enabled demand

8) Addressing social and economic needs for increasing growth and quality of life

9) Data sharing based on interoperable platforms

10) Promoting creativity and innovation, building especially on the use of social networking tools and media by young people.

The main barriers to change and risks indicated by respondents are the following:

\section{Barriers to changes and Risks}

1) ICT Access for all / digital divide

2) Skills and capabilities (of both users and civil servants)

3) Different levels of competences between various levels of governance (municipal/local, regional, national...) and overlapping responsibilities

4) Resistance to change consolidated bureaucratic management practices

5) Lack of financial and human resources (especially due to high initial costs and need of continuous education and training)

6) Lack of culture and mechanisms for new forms of inter-administrative collaboration and customer-orientation

7) Not appropriate legal and regulatory frameworks

8) Lack of interest/motivation for both politicians and citizens in engaging in dialogue and participation, if not effective

9) Too ICT-driven governance models and lack of business understanding of ICTs in the public sector

10) Security, safety and privacy risks 
On the other hand, respondents identified the following as main enablers and opportunities of ICT-enabled governance:

\section{Enablers of changes and Opportunities}

1) Reduction of administrative burdens

2) Establishment of effective PPPs

3) Citizens and civil society organisations' engagement and participation

4) Creation of strong and secure interoperability platforms

5) Integration of front and back-office administrative processes

6) Change of behaviour of civil servants

7) Leadership and clear vision

8) Time \& economic savings

9) Transparency and accountability

10) General educational and socio-cultural context of reference at city level

Finally, in terms of main characteristics of the emerging ICT-enabled governance models, as pointed out by respondents, the following can be mentioned at this initial state of research:

\section{Characteristics of ICT-enabled governance models}

1) Information and data/services sharing based on interoperable, secure and open platforms

2) Better access to all citizens to policy-making processes through citizens' engagement and participation in order to ensure all views are taken into consideration

3) Standardisation of processes and decentralisation of services (including PPPs and outsourcing to civil society organisations and other service providers as mediators)

4) Performance measurement (efficiency and effectiveness) based on result-oriented/customer satisfaction mechanisms of quality control

5) Agile ICT-based and innovative/co-created/co-managed public services

\section{Conclusions and Further Research}

In conclusion, the analysis of survey results provided a quite comprehensive mapping of the use of ICTs in European cities as well as the views of policy makers, city government officials, practitioners and researchers, on the way ICTs are influencing governance processes. The analysis also provided very useful indication on what new ICT-enabled governance models are emerging, and some preliminary classifications of dimensions of change, main drivers, barriers, enablers and characteristics, identifying also opportunities, risks and challenges.

In terms of ICT-driven changes, although most respondents indicate that ICTs are producing significant $(65 \%)$ or very significant changes $(11 \%), 24 \%$ of respondents point out to a limited impact on governance changes due to ICTs. On the one side, in fact, this result brings us to broaden the scope of the analysis to shed lights beyond the technical issues -and difficulties- related to the introduction of ICTs into government systems, on the role of legal, organizational and cultural changes when discussing of 
ICT-enabled governance models. On the other side, this further justifies the need of deeper research in this field, in order to better understand the implications ICTs are having on governance at city level, and the drivers of changes in relation to ICTenabled services and governance innovations.

With specific regard to the policy areas most impacted by ICTs, the survey identifies the pivotal role of ICTs for renewing the Information and Communication policy activities, and with particular regard to citizens' participation and engagement.

However, although the sound sample already may allow to generalize results at EU level and to initiate deeper analysis through case studies, a further effort of analysis of the results of the survey will be conducted to consolidate the findings and substantiate the research dimensions under exploration. In addition to this, and based on the indications emerged from the survey, as well as conceptual work conducted during the next phases of the research a measurement framework will be elaborated by IPTS in collaboration with city government representatives, researchers and practitioners experts in ICT for governance at city level aiming at seeking to capture ICT-driven changes on governance processes in EU cities.

\section{References}

1. Graham, S. (ed.): The Cybercities Reader. Routledge, London (2004)

2. Misuraca, G., Ollé Sanz, E.: Exploring ICT-enabled governance models in European cities: a preliminary analysis towards developing a conceptual and measurement policy impact framework. In: Paper submitted to the 10th European Conference on e-Government (ECEG 2010), June 17-18, 2009, University of Limerick, Ireland (forthcoming 2010)

3. Jacquier, C.: Urban Governance: forging a path between complications and complexity. Paper presented at the Towards New Territorial Governance (2008)

4. Perroux, P.: Dictionnaire économique et social Paris: Haitier (1990)

5. EU: Cohesion Policy and Cities: the Urban Contribution to Growth and Jobs in the Regions (known as the Bristol Accord): European Commission (2006)

6. Jouyet, J.P., Levy, M.: L'économie de l'immatériel. La croissance de demain. Report by the Commission on the intangible economy to the French Industry Minister (2006)

7. Hay, C.: Constructivist Institutionalism. In: Rhodes, R.A.W., Binder, S., Rockman, B. (eds.) The Oxford Handbook of Political Institutions, pp. 56-74. Oxford Univ. Press, Oxford (2006)

8. Schmidt, V.A.: Discursive Institutionalism: The Explanatory Power of Ideas and Discourse. Annual Review of Political Science 11, 303-326 (2008)

9. Berger, P.L., Luckmann, T.: The Social Construction of Reality (1966)

10. Misuraca, G.: e-Government 2015: exploring m-government scenarios, between ICTdriven experiments and citizen-centric implications. Technology Analysis and Strategic Management 21(3), 18 (2009)

11. Misuraca, G.: Social Computing and Governance. In: Punie, Y., Lusoli, W., Centeno, C., Misuraca, G., Broster, D. (eds.) The impact of Social Computing on the EU Information Society and Economy, IPTS, JRC, European Commission (2009) 